\title{
Towards Road Sustainability-Part I: Principles and Holistic Assessment Method for Pavement Maintenance Policies
}

\author{
Anne de Bortoli ${ }^{1, *(\mathbb{D}}$, Adélaïde Féraille ${ }^{2}$ and Fabien Leurent ${ }^{3}$ (i) \\ 1 LVMT, Ecole des Ponts, Université Gustave Eiffel, 4-20 Boulevard Newton, Cité Descartes, \\ Champs-sur-Marne, CEDEX 2, F-77447 Marne-la-Vallée, France \\ 2 Navier Laboratory, Ecole des Ponts, Université Gustave Eiffel, 6-8 Avenue Blaise-Pascal, Cité Descartes, \\ CEDEX 2, F-77455 Marne-la-Vallée, France; adelaide.feraille@enpc.fr \\ 3 CIRED, UMR 8568, Campus du Jardin Tropical, 45 bis Avenue de la Belle Gabrielle, CEDEX 2, \\ F-94736 Nogent-sur-Marne, France; fabien.leurent@enpc.fr \\ * Correspondence: anne.de-bortoli@enpc.fr
}

check for

updates

Citation: de Bortoli, A.; Féraille, A.; Leurent, F. Towards Road Sustainability-Part I: Principles and Holistic Assessment Method for Pavement Maintenance Policies. Sustainability 2022, 14, 1513. https:// doi.org/10.3390/su14031513

Academic Editors: Joel R.M. Oliveira, Hugo Silva, R. Christopher Williams and Zejiao Dong

Received: 11 December 2021

Accepted: 19 January 2022

Published: 28 January 2022

Publisher's Note: MDPI stays neutral with regard to jurisdictional claims in published maps and institutional affiliations.

Copyright: (C) 2022 by the authors. Licensee MDPI, Basel, Switzerland. This article is an open access article distributed under the terms and conditions of the Creative Commons Attribution (CC BY) license (https:// creativecommons.org/licenses/by/ $4.0 /)$.

\begin{abstract}
Assessing the holistic sustainability of public policies remains a challenge rarely taken up due to a lack of adequate assessing methods. Frequently, only environmental and/or financial aspects are addressed, rather than the three pillars, including macro- and micro-economic as well as social performance. This paper presents an assessment method to fully compare the performance of pavement resurfacing policies for all its stakeholders and considering pavement-vehicle interactions. First, an analytical and then systemic approach to road maintenance highlights all its stakeholders, and a complete set of sustainability indicators is proposed to quantify the various impacts of maintenance programs: tax revenues, road operator's and users' savings, domestic production and employment, net present value, users' time savings and noise reduction health benefits, as well as protection of natural resources, biodiversity and human health. Second, specific physical models of road condition (International Roughness Index) and its role in pavement-vehicle interaction in terms of vehicle consumption and wear as well as traffic noise are introduced. Then, equations to calculate these indicators are presented based on a comparison of existing assessment methods. The final transdisciplinary method pulls from road engineering, industrial ecology, acoustics and economics. It especially combines environmental and economic life cycle assessments and economic inputoutput analysis, as well as financial and socioeconomic appraisals. Finally, this article takes up the interdisciplinary challenge of building a fully holistic assessment method to help decision makers properly address sustainability, and its general algorithm can be adapted to assess a variety of transportation policies.
\end{abstract}

Keywords: holistic sustainability; road maintenance policies; multicriteria decision making support; life cycle assessment; macroeconomics; socioeconomic appraisal; public investments; pavementvehicle interaction

\section{Introduction}

The sustainability of road transportation strongly depends on infrastructure maintenance policies, but the impacts of these policies have never been quantified with a comprehensive triple bottom line framework. As an example, in France, road transportation accounts for $8 \%$ of jobs and $13 \%$ of the gross domestic product, and it generates annual tax revenues of EUR 45 billion [1]. The average household spends more than $10 \%$ of its budget on cars [2]), and the average individual spends a cumulative period of 4 years on the road in their life (calculated from the French households transportation survey [3]). These socioeconomic figures have concomitant environmental implications, as $29 \%$ of primary energy consumption [4] and $28 \%$ of greenhouse gas (GHG) emissions [5] are attributable to road transportation in the country. Road vehicles are also responsible for local pollution, particularly particulate matter emissions, including PM2.5, that alone would cause almost 
10,000 annual deaths in France (see Supplementary Material). Moreover, the impact of road noise affects 16 million people, around 1 million of them at critical health thresholds [6].

Road conditions - and thus pavement maintenance policies-influence this performance. For instance, road surface deterioration increases consumption and wear for the vehicles traveling over them due to pavement-vehicle interactions (PVI) [7], thereby affecting the overall efficiency of the road and especially its environmental performance [8]. Nevertheless, the holistic sustainability of pavement maintenance policies has never been assessed comprehensively. While some methods were developed to make triple bottom line assessments of specific activities or products, such as buildings in Turkey [9], small and medium manufacturing companies [10] or urban food system governance [11], methods are still needed for transportation [12] and its infrastructure maintenance plans. Numerous methods claim a sustainability approach while being in fact mono-pillar, i.e., considering only one of the three dimensions: social, environmental or economic.

The main objective of this article is to build a comprehensive method to assess the holistic sustainability of road maintenance policies, with a focus on pavement resurfacing and PVI. Indeed, besides major refurbishments, pavement resurfacing is the most common and important kind of road maintenance operation, consisting of (re)building the top layer of a road surface, by spreading road materials over a thickness of 1 to less than $10 \mathrm{~cm}$. This paper's subobjectives are as follows: first, to define road maintenance stakeholders and the categories of holistic sustainable impacts affecting them; second, to introduce specific physical models of road condition (international roughness index (IRI)) and its role on the pavement-vehicle interaction in terms of vehicle consumption and wear as well as traffic noise and third, to put forward a set of equations to fully specify the assessment model and make it computable. A companion article "Part II" will present a case study on maintenance policies for an interurban highway in France and show the practicability of the method and its concrete usefulness.

\section{Literature Review}

\subsection{Mono-Pillar Sustainability Methods and Hybridization}

Fairly extensive literature exists on the environmental evaluation of roads through life cycle assessment (LCA) [13], sometimes used specifically for the question of resurfacing [14-21]. Life cycle cost analysis (LCCA) can also be used to financially optimize roads [22-25]. Next, the input-output analysis (IOA) approach ([26] is an operational method for grasping the macroeconomic impacts of an economic policy on domestic production and employment [27]. It has been used in the transportation sector to assess the impact of a new road in the U.S. [28] or in France [29], of rolling out electric vehicles in France [30] or of the Paris-Bordeaux high-speed rail line in France [31], but never for road resurfacing. Finally, hybrid methods are used to assess the impact of roads excluding road maintenance. For example, a socioeconomic appraisal method is used by the French Ministry of Transportation to assess the public utility of a new transportation infrastructure, which combines macroeconomic, financial, social (time saved) and environmental dimensions [29]. This method has been hybridized with LCA in the case of an urban road rehabilitation operation [32]. However, it is not suitable for analyzing maintenance and there are deficiencies in its scope. Moreover, whole life cost analysis-hybridizing LCA and LCCA—was recently used in a pavement management study [33].

\subsection{PVI Models and Road Maintenance Sustainability}

Many models of vehicle operating costs have been developed since the 1970s [7]: incremental models linking the IRI with vehicle consumption and wear were developed for the World Bank between 1971 and 2005 by the Massachusetts Institute of Technology (MIT) [34], the Transportation Research Lab [35-37] and Birmingham University [38]. Originally developed for roads and vehicles in developing countries, these models were first calibrated for a developed country in the U.S. by Michigan State University [7]. This calibration reveals consumption differences of around $3 \%, 8 \%$ and $130 \%$ in fuel, tires and 
suspension systems, respectively, between vehicles traveling on a very smooth surface $(I R I=1 \mathrm{~m} / \mathrm{km}$ ) and vehicles running on a road in fairly poor condition (IRI $=6 \mathrm{~m} / \mathrm{km}$ ), these percentages depending on the vehicle type and its roll speed.

Finally, several studies have assessed some sustainability consequences of vehicle consumption due to road surface conditions. We summarize the characteristics of these studies in Table 1 and describe them further.

Table 1. Characteristics of road assessments considering PVI.

\begin{tabular}{|c|c|c|c|c|c|c|c|c|}
\hline \multirow{2}{*}{ Lead Author and Year } & \multicolumn{4}{|c|}{ Indicators } & \multicolumn{4}{|c|}{ Consumption of Goods } \\
\hline & Costs & GHG & Energy & Others & Roadworks & Fuel & Tires & Suspension Parts \\
\hline Wang 2012b & & $x$ & $x$ & & $x$ & $x$ & & \\
\hline Chong 2017 & & $x$ & $x$ & & $X$ & $x$ & & \\
\hline Wang 2014 & $X$ & $x$ & & & $x$ & $x$ & & \\
\hline Bryce 2014 & & & $x$ & & $x$ & $x$ & & \\
\hline Yu 2015 & & $x$ & $x$ & $X(\mathrm{LCA})$ & $x$ & $x$ & & \\
\hline Yang 2015 & $x$ & $x$ & $x$ & & $x$ & $x$ & & \\
\hline Santos 2015 & & $x$ & $x$ & $X(\mathrm{LCA})$ & $X$ & $x$ & & \\
\hline Santos 2017 & $x$ & $x$ & $x$ & $X(\mathrm{LCA})$ & $x$ & $x$ & & \\
\hline Pellecuer 2014 & & $x$ & $x$ & $X(\mathrm{LCA})$ & $X$ & $X$ & & \\
\hline Guevara 2017 & $X$ & & & Time & $x$ & $x$ & $X$ & $x$ \\
\hline
\end{tabular}

The models of vehicle consumption sensitivities to the IRI established by Chatti and Zaabar [7] have been used several times to assess the effectiveness of road maintenance practices. Wang et al. [8] compared the improvements in GHG emissions and energy consumption obtained from a resurfacing program leading to a lower than usual IRI, including in the scope of their assessment both the impact of roadwork and the fuel consumption of the vehicles traveling on the roads. Chong and Wang [39] conducted a fairly similar study, extending the latter approach with an optimization program considering the initial dimensions of the road. Wang, Harvey and Kendall [40] assessed the optimum potential gain in GHG emissions in relation to road maintenance policy in the State of California and calculated the cost of mitigation in dollars per ton of $\mathrm{CO}_{2}$ equivalent saved. Bryce et al. [41] presented a five-year optimization model that minimizes total energy consumed in both road maintenance and fuel consumption, constrained by the road operator's costs and road conditions. Yu et al. [42] developed an optimization program of the same type, extending the environmental scope to GHG emissions, acidification potential and respiratory effects, using a weighting method. Yang et al. [43] compared the impact of resurfacing programs with differences in the proportion of reclaimed asphalt pavement included in the new resurfacing material from an environmental perspective-GHG emissions and primary energy consumption - and from the perspective of the financial impact on the road operator. The only environmental effect from PVI considered was fuel consumption. Similarly, Santos et al. [44] compared the environmental performance of several resurfacing techniques but also left out the impact of differences in tire and suspension wear arising from PVI. This performance was assessed using the environmentally extended input-output method but not LCA in a second comparative study considering tires and suspension parts [33]. The latter study also includes an economic performance indicator, in the form of net present value (NPV), including the economic flows associated with road maintenance as well as vehicle consumption, calculated with a single discount rate of $2.3 \%$. A decision support method for road surface management, developed by Pellecuer et al. [45], calculates the monetized health impacts of road noise and atmospheric pollution, as well as the cost of carbon dioxide emissions associated with traffic, under different road surface conditions. It also includes the variation in fuel consumption but not wear on tires and suspension. This study considers the monetary cost of noise pollution.

Finally, the marginal effect of vehicle consumptions according to road condition on the time spent by the users to operate their vehicle is considered by Guevara [46]. Nevertheless, 
no studies have compared the excess time spent because of roadwork with the time saved on the logistics of vehicle consumptions (journeys to gas stations to fill up and to service stations for tire and suspension maintenance).

\subsection{Article's Scientific Contributions}

As shown in the literature review, the methods developed to assess the sustainability of road maintenance policies are numerous but fragmentary with respect to the range of impacts on sustainable development and on stakeholders, as well as in consideration of the consequences of PVI. We thus propose a method that completes the existing approaches by adding the social, macroeconomic and financial aspects missing in the literature and by considering all the consequences of PVI-in particular the previously neglected environmental contributions of tire and suspension system wear. A novel method is also integrated to quantify the impact of road pavement resurfacing on traffic noise over time and ultimately damage to road local residents' health.

\section{Method Overview}

\subsection{Identifying Road Maintenance Stakeholders and a Comprehensive Classification of Impacts}

We built the method based on a reflection on which fundamental goals a public policy should follow towards a sustainable pathway, considering all four thinking schemes of socioeconomic ethics [47], main findings of the economics of welfare [48] and happiness [49] and the analysis of the original French texts theoretically driving the national social contract [50-52]. After a thorough analysis, the socioeconomic factors of happiness which are related to the strategies of road maintenance are: health, safety and security, employment, leisure and free time, resources and natural environment (details are available in the Supplementary Material and a Ph.D. thesis manuscript [53]). These factors affect the following stakeholders: the asset manager (i.e., road operator), the users, the residents, the State (or Government) and the environment.

Then, from a road maintenance stakeholder analysis and the multiple interests underlined in the literature review, we selected a set of indicators to holistically assess the multiattribute performance of a road resurfacing policy. The number of indicators was arbitrarily restricted to around 10 to avoid decision making cognitive saturation [54]. Nonquantitative impacts such as user comfort were not considered, and road safety was not accounted for due to its inherent multifactorial aspect, only partially depending on the infrastructure itself [55], thus difficult to separate from the other factors. Finally, the set of eleven indicators is composed of: users' time savings, health protection related to road noise, protection of resources, biodiversity and human health, road operator's and users' savings, domestic production and employment, tax revenue and national economic savings.

The stakeholders, impact causality chains and selected indicators are illustrated in the Figure 1. It shows how PVI are at the center of the stakeholders' impacts. 


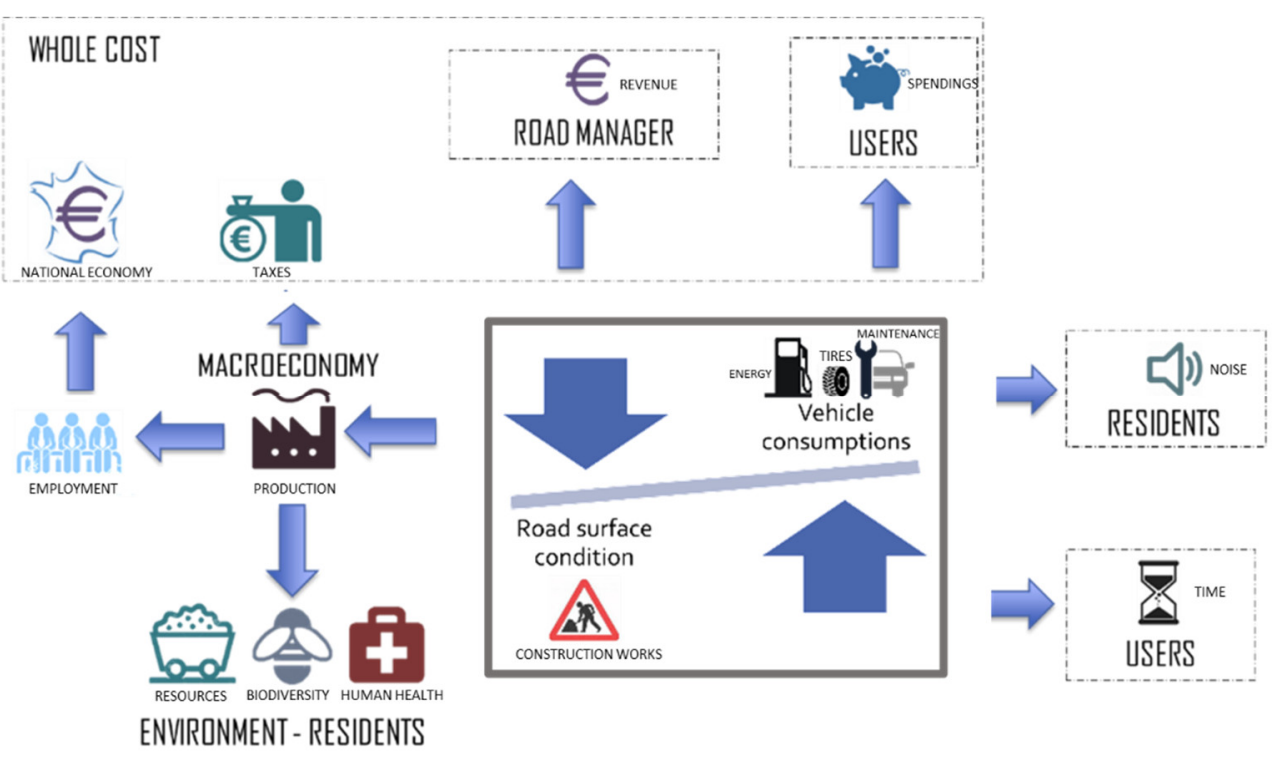

Figure 1. Systemics of road maintenance impacts: stakeholders' analysis, causality chains and impact categories per stakeholder.

\subsection{Overview of the Method's Architecture}

The architecture of the integrated method that we developed to assess the different indicators selected in Figure 1 is represented in Figure 2. As an input, it uses IRI data of the road studied at the time $t_{0}$. Depending on the pavement resurfacing scheme, it simulates the evolution of the IRI over time and calculates the associated inventories of consumptions and emissions on the assessment period: road works and vehicle consumptions, as well as noise emissions. It then combines assessment methods covering all aspects relating to road maintenance sustainability for the stakeholders: whole cost analysis, financial and socioeconomic assessments, LCA and Leontief's IOA. Combining these methods allows for calculating the main impacts caused by a maintenance policy as a result of the speed and intensity of road surface deterioration throughout its lifespan and on the different stakeholders highlighted previously.

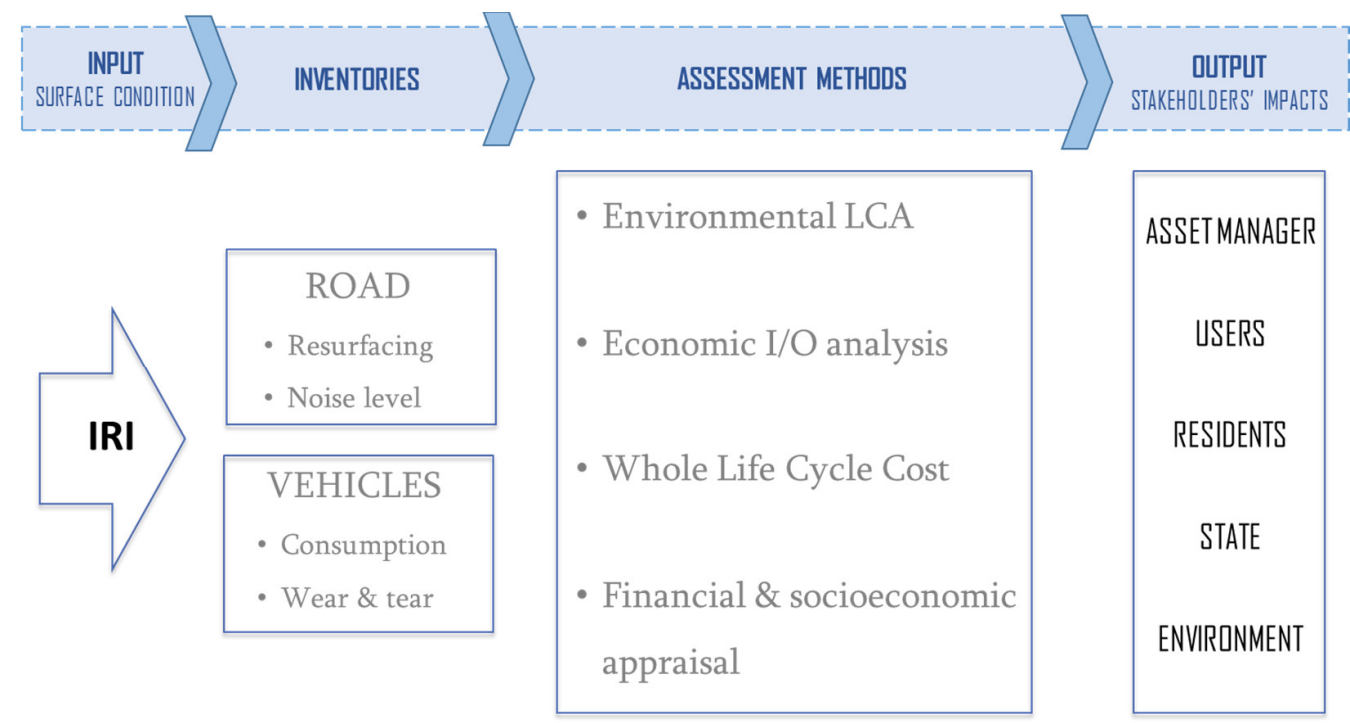

Figure 2. Architecture of the integrated method to assess the sustainability of pavement resurfacing programs (IRI: international roughness index; LCA: life cycle assessment; I/O: input-output). 


\subsection{Practical Use of the Method}

The method was developed to be applied at the scale of the road section. The section must be considered over an observation period that is long enough to contain several resurfacing cycles and where the physical condition of the section is identical at the end of the analysis period for all the maintenance plans considered. A maintenance plan consists of a temporal sequence of resurfacing operations. Several resurfacing techniques exist, differing in terms of the thickness of the materials used, the quality of these materials and the construction technique of the surface layer. Each technique presents a specific financial, macroeconomic and environmental performance profile from the point of view of the maintenance operation. On the other hand, each maintenance technique has a potentially different impact on road surface condition and therefore the consumption and wear of the vehicles it supports. The vehicle population carried by the road section is separated into different categories of vehicles. The different consequences of PVI on these categories in terms of consumption and wear are accounted for. The impacts of this consumption and wear, as well as those of road works, are considered over their entire life cycles, as macroeconomic, financial and environmental consequences happen over their entire supply chain. The environmental aspects quantified are therefore calculated on a global scale. On the other hand, the health impact of road noise for residents relates to a local and not a global indicator. Finally, macroeconomic indicators focus on a national approach.

\section{Specific Physical Models}

\subsection{Capturing the Evolution of Road Surface Condition}

Considering the literature, the surface condition is expected to be a key parameter of road maintenance sustainability. From the IRI data for the road section to be assessed from time $t_{0}$, we calculate the evolution of the IRI over the entire lifespan of the road surface, between two resurfacing operations and before/after resurfacing operations.

\subsubsection{IRI Evolution between Two Resurfacing Operations}

The studies published on changes in the IRI between two resurfacings $[8,23,43,56-60]$ propose different formulas in the mathematical form described in Equation (1)-where $a, b$ and $d$ are calibration parameters, and $t$ is time.

$$
\operatorname{IRI}(t)=a(t+b)^{d}
$$

In previous studies, this ultimately corresponds to deterioration speeds ranging from $0.019 \mathrm{~m} / \mathrm{km}$.year [60] to $0.23 \mathrm{~m} / \mathrm{km} \cdot$ year [59]. We recommend calibrating the equation for every road section or network assessed using field measures.

\subsubsection{Effect of Resurfacing Operations on the IRI}

The effect of resurfacing works on the IRI can be estimated by calibrating the American equation established by Wang et al. [59] using the IRI data for the road assessed as recalled in Equation (2), where e and $g$ are calibration coefficients depending on the resurfacing technique, $t_{R+}$ the time just after resurfacing and $t_{R-}$ the time just before.

$$
I R I\left(t_{R+}\right)=e \times I R I\left(t_{R-}\right)+g
$$

By default, for a resurfacing technique with a thickness between 3 and $7.5 \mathrm{~cm}$, one can take the parameter values of the study referred to, recalculated here in international system units: $e=0.40$ and $g=0.67 \mathrm{~m} / \mathrm{km}[59]$.

\subsection{Consumptions and Emissions over the Pavement Surface's Lifetime}

Vehicle consumptions and emissions partly depend on the IRI, which partly depends on the resurfacing program and thus on maintenance operations. To compare the sustainability of different road maintenance programs, we assess for each option the resurfacing 
works demand, the vehicle consumptions - in fuel, tires and shock absorbers - as well as the road noise emissions. PVI intensity and consequences depend on the kind of vehicle considered. To model the traffic, we choose a typology with 4 categories of vehicles like Chatti and Zaabar's method [7]: passenger car (PC), light commercial vehicle (LCV), small heavy vehicle (2 axles) (SHV) and large heavy vehicles (3 axles and more) (LHV).

\subsubsection{Resurfacing Works Demand}

Based on the resurfacing programs to be tested, with Equation (3), we calculate the resurfacing works demand $R W D_{k}$ (in square meters) using a resurfacing technique $k$ depending on the width $\omega$ of the pavement to be resurfaced in meters, its length $\lambda$ in meters and $N_{k}$, the number of resurfacing operations of type $k$ over the assessment period.

$$
R W D_{k}=\omega \times \lambda \times N_{k}
$$

\subsubsection{Excess Vehicle Consumptions}

Based on the data for pavement condition and dynamic traffic over time, we calculate the excess consumptions due to pavement surface irregularities over the pavement's lifetime for each vehicle category and consumable type-fuel, tires and suspensions. To do this, we consider the French average consumptions and select, after a model comparison, the IRI consumption sensitivity factor from HDM-4 [38] calibrated for the U.S. [61], which we adapt to the speeds actually observed on the different types of French road networks by statistical regression (see Supplementary Material). French speed limits are very similar to those in other European countries, but the equation adaptations can be conducted using the same method for each country's real conditions.

\section{- $\quad$ Excess fuel consumption}

The equations to quantify excess fuel consumption (EFC), depending on IRI, vehicle type and road type, are calculated in the Supplementary Material and presented in Table 2 for each kind of intercity network in France considering the average speeds on these networks in $\mathrm{km} / \mathrm{h}$ for light vehicles (LV) - PC and LCV_-and heavy vehicles (HV) - SHV and LHV. Again, regressions can be calculated using the same method for each country's real conditions.

Table 2. Equations to calculate EFC depending on IRI and type of vehicle and road.

\begin{tabular}{|c|c|c|c|}
\hline & & $\mathrm{EFC}=\mathbf{f}(\mathrm{IRI})$ & $\mathbf{R}^{2}$ \\
\hline \multirow{4}{*}{ Highways (118/88) } & PC & $\mathrm{EFC}=0.0233 \mathrm{IRI}+0.975$ & 0.9927 \\
\hline & LCV & $\mathrm{EFC}=0.00710 \mathrm{IRI}+0.996$ & 0.9317 \\
\hline & Small HV & $\mathrm{EFC}=0.00870 \mathrm{IRI}+0.992$ & 0.9939 \\
\hline & Large HV & $\mathrm{EFC}=0.0170 \mathrm{IRI}+0.981$ & 0.9799 \\
\hline \multirow{4}{*}{$\begin{array}{c}\text { Express ways } \\
(101 / 84)\end{array}$} & PC & $\mathrm{EFC}=0.0239 \mathrm{IRI}+0.975$ & 0.9966 \\
\hline & LCV & $\mathrm{EFC}=0.0079 \mathrm{IRI}+0.994$ & 0.9694 \\
\hline & Small HV & $\mathrm{EFC}=0.0092 \mathrm{IRI}+0.991$ & 0.9975 \\
\hline & Large HV & $\mathrm{EFC}=0.0177 \mathrm{IRI}+0.980$ & 0.9823 \\
\hline \multirow{4}{*}{$\begin{array}{l}\text { National/rural roads } \\
\qquad(82 / 79)\end{array}$} & PC & $\mathrm{EFC}=0.0245 \mathrm{IRI}+0.976$ & 0.9983 \\
\hline & LCV & $\mathrm{EFC}=0.0088 \mathrm{IRI}+0.993$ & 0.9914 \\
\hline & Small HV & $\mathrm{EFC}=0.0097 \mathrm{IRI}+0.991$ & 0.9996 \\
\hline & Large HV & $\mathrm{EFC}=0.0185 \mathrm{IRI}+0.980$ & 0.9848 \\
\hline
\end{tabular}

Fuel consumption due to the deterioration of the surface of the road over time can be calculated using Equation (4):

$$
F C_{j, k}=\lambda \times \sum_{i} \int_{t_{0}}^{t_{f}} E F C_{j, i}(t) \times A F C_{i, j}(t) \times Q_{j}(t)
$$


with $F C_{j, k}$ the fuel volume of type $k$ overconsumed on a road of type $i$ over a period from $t_{0}$ to $t_{f}$ in hundredths of liters, $\lambda$ the length of the road section evaluated in kilometers, $E F C_{j, i}$ the EFC of a vehicle of type $j$ on a road of type $i$ in percentage, $A F C_{i, j}$ the dynamic average fuel consumption of a vehicle of type $j$ on a road of type $i$ in liters per $100 \mathrm{~km}$ and $Q_{j}$ the traffic flow of type $\mathrm{j}$ vehicles on the road section considered in number of vehicles.

- $\quad$ Excess tire wear

The equations to calculate excess tire wear (ETW), depending on IRI, vehicle type and road type, are calculated in the Supplementary Material and presented in Table 3. for each kind of intercity network in France and LV and HV average speeds, respectively. Specific national regressions can be calculated using the same method for any country.

Table 3. Equations to calculate ETW depending on IRI and type of vehicle and road.

\begin{tabular}{cccc}
\hline & Vehicle & ETW $=$ f (IRI) & $\mathbf{R}^{\mathbf{2}}$ \\
\hline \multirow{3}{*}{ Highways (118/88) } & PC & ETW $=0.0168$ IRI + 0.9812 & 0.9854 \\
& LCV & ETW $=0.0102$ IRI + 0.9927 & 0.9687 \\
& Small HV & ETW $=0.0122$ IRI + 0.9866 & 0.9907 \\
& Large HV & ETW $=0.0089$ IRI + 0.9917 & 0.9983 \\
\hline \multirow{2}{*}{$\begin{array}{c}\text { Express ways } \\
(101 / 84)\end{array}$} & PC & ETW $=0.0136$ IRI + 0.9856 & 0.9884 \\
& LCV & ETW $=0.0088$ IRI + 0.9929 & 0.9776 \\
Small HV & ETW $=0.0012$ IRI + 0.987 & 0.9921 \\
Lational/rural roads & PC & ETW $=0.0085$ IRI + 0.9923 & 0.9972 \\
$(82 / 79)$ & LCV & ETW $=0.0100$ IRI + 0.9905 & 0.9865 \\
& Small HV & ETW $=0.0073$ IRI + 0.9931 & 0.9839 \\
& Large HV & ETW $=0.0117$ IRI + 0.9874 & 0.9938 \\
\hline
\end{tabular}

Tire consumption due to the deterioration of the surface of the road over time can be calculated using Equation (5):

$$
T C_{i, k}=\lambda \times \sum_{i} \int_{t_{0}}^{t_{f}} E T W_{i, j}(t) \times T W R_{i, j}(t) \times Q_{j}(t)
$$

with $T C_{i, k}$ the number of tires of type $k$ overconsumed on the road of type $i, \lambda$ the length of the road section evaluated (in kilometers), $E T W_{i, j}$ the ETW for a vehicle of type $\mathrm{j}$ on a road of type $i, T W R_{i, j}$ the kilometric tire wear ratio for a vehicle of type $j$ on a road of type $i$ and $Q_{j}$ the traffic flow of type $i$ vehicles.

\section{- $\quad$ Excess suspension wear}

According to Chatti and Zaabar's model, vehicles age faster on roads only with IRIs over $3 \mathrm{~m} / \mathrm{km}$. In our model, we will consider that only the suspension systems age faster under high IRIs. Over the $3 \mathrm{~m} / \mathrm{km}$ threshold, the equations to calculate the shock absorber lifespan, depending on IRI, vehicle type and road type, are calculated in the Supplementary Material and presented in Table 4, for each kind of intercity network in France and LV and $\mathrm{HV}$ average speeds, respectively. These equations can be recalculated for any network in any country using the same process presented in the Supplementary Material. 
Table 4. Equations to calculate the shock absorber lifespan (SAL) depending on IRI and type of vehicle and road.

\begin{tabular}{|c|c|c|c|}
\hline & & $S A L=\mathbf{f}(I R I)$ & $\mathbf{R}^{2}$ \\
\hline \multirow{4}{*}{ Highways (118/88) } & PC & $\mathrm{SAL}=139643 . \exp (-0.183 * \mathrm{IRI})$ & 0.9750 \\
\hline & LCV & SAL $=139643 . \exp (-0.183 *$ IRI $)$ & 0.975 \\
\hline & Small HV & $\mathrm{SAL}=218765 \cdot \exp (-0.271 * \mathrm{IRI})$ & 0.9874 \\
\hline & Large HV & $\mathrm{SAL}=181842 \cdot \exp (-0.207 * \mathrm{IRI})$ & 0.9651 \\
\hline \multirow{4}{*}{$\begin{array}{l}\text { Express ways } \\
(101 / 84)\end{array}$} & PC & $\mathrm{SAL}=155221 . \exp (-0.183 * \mathrm{IRI})$ & 0.9750 \\
\hline & LCV & $\mathrm{SAL}=155$ 221.exp $(-0.183 * \mathrm{IRI})$ & 0.975 \\
\hline & Small HV & $\mathrm{SAL}=226487 \cdot \exp (-0.271 * \mathrm{IRI})$ & 0.9874 \\
\hline & Large HV & $\mathrm{SAL}=188260 . \exp (-0.207 * \mathrm{IRI})$ & 0.9651 \\
\hline \multirow{4}{*}{$\begin{array}{l}\text { National/rural roads } \\
\qquad(82 / 79)\end{array}$} & PC & $\mathrm{SAL}=177$ 331.exp $(-0.183 * \mathrm{IRI})$ & 0.9750 \\
\hline & LCV & $\mathrm{SAL}=177331 \cdot \exp (-0.183 * \mathrm{IRI})$ & 0.975 \\
\hline & Small HV & $\mathrm{SAL}=236940 \cdot \exp (-0.271 * \mathrm{IRI})$ & 0.9874 \\
\hline & Large HV & SAL $=196949 \cdot \exp (-0.207 *$ IRI $)$ & 0.9651 \\
\hline
\end{tabular}

Shock absorber consumption for IRIs above $3 \mathrm{~m} / \mathrm{km}$ can be calculated using Equation (6):

$$
S A C_{i, k}=\lambda \times \sum_{i} \int_{t_{0}}^{t_{f}} \frac{1}{S A L_{i, j}(t)} \times Q_{j}(t)
$$

with $S A C_{i, k}$ the number of shock absorbers of type $k$ consumed on the road type $i, \lambda$ the length of the road section evaluated (in kilometers), $S A L_{i, j}$ the SAL for a vehicle of type $j$ on a road of type $i$ and $Q_{j}$ the traffic flow of type $j$ vehicles.

Note that this time, we directly calculate a consumption rather than an overconsumption: this does not change the final calculation, as it will be conducted on a differential approach between resurfacing programs.

\subsubsection{Noise Emission}

- Unitary noise linear power level over time

Noise characterization can be calculated through the unitary noise linear power level $(\mathrm{Lw} / \mathrm{m})$ corresponding to the noise power emitted by one vehicle on one meter. To understand its evolution over time, the statistical models of tire-road noise evolution from the European benchmark method [62] are updated using the most recent version of the French road noise database established by the CETE of East, a public technical center that reports to the French Ministry of Transportation (see Supplementary Material). These new models, different for heavy vehicles (HVs) and light vehicles (LVs), are presented in Table 5. $\mathrm{Rx}$ corresponds to acoustic categories of pavement rolling course, these categories being detailed in the Supplementary Material. Although the model is updated using a French database, physical acoustic phenomena is the same everywhere; thus, it must be usable in other countries with similar climate conditions, where pavement ageing is equivalent.

Table 5. Unitary noise linear power level per size of vehicle, depending on the pavement age $t$ (in year), for $\mathrm{t}>2$ years and for three different categories of pavement surface $\mathrm{Rx}$.

\begin{tabular}{lcc}
\hline Rx & Light Vehicles & Heavy Vehicles \\
\hline R1 & $2.2 \ln (\mathrm{t}-1)+\mathrm{Lw} / \mathrm{m}(\mathrm{t}=2$ years $)$ & $1.3 \ln (\mathrm{t}-1)+\mathrm{Lw} / \mathrm{m}(\mathrm{t}=2$ years $)$ \\
$\mathrm{R} 2$ & $2.7 \ln (\mathrm{t}-1)+\mathrm{Lw} / \mathrm{m}(\mathrm{t}=2$ year $)$ & $1.6 \ln (\mathrm{t}-1)+\mathrm{Lw} / \mathrm{m}(\mathrm{t}=2$ years $)$ \\
& $\left\{.2(\mathrm{t}-2)+\frac{\mathrm{Lw}}{\mathrm{m}(\mathrm{t}=2 \text { years })}\right.$ if $\mathrm{t} \in[2 ; 10]$ \\
$\frac{\mathrm{Lw}}{\mathrm{m}(\mathrm{t}=10 \text { years })}$ if $\mathrm{t}>10$ & $\left\{\begin{array}{c}0.125(\mathrm{t}-2)+\frac{\mathrm{Lw}}{\mathrm{m}(\mathrm{t}=2 \text { years })} \text { if } \mathrm{t} \in[2 ; 10] \\
\frac{\mathrm{Lw}}{\mathrm{m}(\mathrm{t}=10 \text { years })} \text { if } \mathrm{t}>10\end{array}\right.$ \\
\hline
\end{tabular}


- Total linear power level per vehicle

The noise of one motorized vehicle rolling on pavement is calculated by adding two noise components: the noise emitted by the motor and the noise emitted by the tireroad interaction. To calculate the unitary noise linear power level at $t=2$ years, $\mathrm{Lw} / \mathrm{m}$ ( $t=2$ years) per component and type of vehicle, we use formulas from Sétra [62] detailed in the Supplementary Material in the conditions of French interurban roads. We obtain Table 6.

Table 6. Average noise power level-motor and tire-road components-per meter of source line for a two-year-old rolling course.

\begin{tabular}{|c|c|c|c|c|c|c|c|c|c|c|c|c|}
\hline & \multirow{2}{*}{\multicolumn{3}{|c|}{$\begin{array}{c}\text { Lw/m-Motor Component } \\
(\mathrm{dB}(\mathrm{A}))\end{array}$}} & \multicolumn{9}{|c|}{ Lw/m-Tire-Road Component (dB(A)) } \\
\hline & & & & \multicolumn{3}{|c|}{$\mathbf{R} 1$} & \multicolumn{3}{|c|}{$\mathbf{R} 2$} & \multicolumn{3}{|c|}{$\mathbf{R} 3$} \\
\hline & DR/NR & ER & HR & DR/NR & ER & HR & DR/NR & ER & HR & DR/NR & ER & HR \\
\hline $1 \mathrm{LV}$ & 42 & 43 & 43 & 49 & 50 & 52 & 53 & 54 & 56 & 55 & 57 & 58 \\
\hline $1 \mathrm{HV}$ & 50 & 50 & 51 & 59 & 60 & 60 & 62 & 63 & 63 & 63 & 64 & 64 \\
\hline
\end{tabular}

$\mathrm{DR}$ = department road; $\mathrm{NR}$ = national road; $\mathrm{ER}$ = express road; $\mathrm{HR}$ = highway road.

We can then calculate $\mathrm{Lw} / \mathrm{m}(\mathrm{t}=2$ years) per type of vehicle (LV or HV) by adding the noise source $u$-motor and tire-road noise-using the generic noise addition Equation (7).

$$
L_{\text {tot }}=L\left(\sum_{u} \text { Source }_{u}\right)=10 \log \left[\sum_{u} 10^{\frac{L_{u}}{10}}\right]
$$

- Total linear power level per road lane

From the calculation of these linear power levels (emitted by an HL or an LV) for a pavement surface of category $\mathrm{Rx}$ of age $\mathrm{t}$ (tire-road noise component only), the total linear power level per road lane can be calculated by adding the noise of all the vehicles by period of time-day or night. To do so, Equation (8) is the formula to calculate the linear density $\rho_{j}$ in vehicles of type $j$ per meter, with $q_{j}$ the traffic in number of vehicles $j$ per hour and $V j$ the average speed for vehicles of type $j$.

$$
\rho_{j}=\frac{q_{j}}{V j \times 1000}
$$

Then, Equation (9) is the formula to calculate $L$, the noise level of a road per meter depending on the linear density of heavy and light traffic $d_{L V}$ and $d_{H V}$ during the day (6 a.m. to 10 p.m.) or the night (10 p.m. to 6 a.m.) and the noise level of one HV and LV $L_{L V}$ and $L_{H V}$ per meter.

$$
L\left(\sum_{L V+H V} j\right)=10 \log \left[\rho_{L V} 10^{\frac{L_{L V}}{10}}+\rho_{H V} 10^{\frac{L_{H V}}{10}}\right]
$$

- Additivity of the line sources' noises and temporal weighting

In the case of multiple road lanes, the noise of each line source must be added to obtain the linear power level of the road. Several methods can be considered to add the line sources' noise levels, depending on the road and noise receptor configuration. The method must be selected depending on the configuration studied.

- Calculation of the sound power

With Equation (10), we then calculate the sound power $W_{/ m}$ emitted by the traffic from the linear power levels of the road, using Equation (9), with $W_{0, \text { linear }}=1 \mathrm{pW} / \mathrm{m}=$ $1 \times 10^{-12} \mathrm{~W} / \mathrm{m}[63]$.

$$
W_{/ m}=W_{0, \text { linear }} \times 10^{\frac{L_{w / m}}{10}}
$$


The sound level is then integrated over the length $\lambda$ of the road section studied to obtain the average sound powers during the day $(W j)$ or the night $(W n)$ according to the following Equation (11):

$$
W_{\text {tot }}=\int_{0}^{l} W_{/ m} d l=W_{/ m} \times \lambda
$$

This result is then converted into acoustic energy emitted by multiplying by the time period considered. Our sound energy varying with the aging of the road surface and the latter being calculated over a time step of one year, we therefore multiply $W_{\text {tot }}$ by $3600 \mathrm{~s} \times 365$ days $\times$ the number of hours of the period considered $(16 \mathrm{~h}$ for the day and $8 \mathrm{~h}$ for the night) to obtain $E j$ and $E n$, respectively, the daytime and nighttime acoustic energies emitted in $J(A)$.

\section{Three Pillar Indicators' Algorithm}

The classification of performance indicators between the three pillars of sustainable development is a matter of perspective when an indicator can be attached to two or three pillars. We propose the following classification, recognizing this potential intrinsic overlap. The method aims to assess the benefits of an alternative maintenance scheme (Alt) compared to a business-as-usual (BAU) program. Thus, performance indicators will always be calculated as the difference between the alternative scheme's performance and the BAU scheme, using the generic Equation (12):

$$
\begin{aligned}
\operatorname{Benefit}(\text { Alt })=\text { NegativeImpact(BAU })- \text { NegativeImpact }(\text { Alt }) \\
=\text { PositiveImpact(Alt })- \text { PositiveImpact(BAU) }
\end{aligned}
$$

\subsection{Environmental Metrics}

\subsubsection{LCA: Characterization Methods and Indicators}

We use LCA to evaluate the environmental impacts, following ISO standards 14040 and $14044[64,65]$. This method quantifies the environmental impact of a system-being a product or an activity-by inventorying input and output flows crossing the system over its life cycle and calculating their impact on the environment using characterization methods. The inputs and outputs are product, energy or material flows. Input flows come from the natural environment or the technosphere. Based on this inventory, characterization methods relate the flows to their potential impact on the environment, potentially considering their fate and the exposure of specific ecosystems. These methods make it possible to calculate many different environmental impacts, and the same type of indicator-e.g., impact on climate change, acidification or eutrophication-can be calculated in multiple ways depending on the characterization method chosen. The quality of a characterization method depends on the good representativeness of the physical realities modeled: the method must be scientifically up-to-date and adapted to the area of assessment. Two kinds of LCA indicators exist: midpoint and endpoint indicators. Midpoint indicators focus on single environmental problem — such as climate change or acidification-while endpoint indicators aggregate midpoint indicators in the three areas of environmental protection: natural resources, ecosystems and human health. A complete midpoint indicator set has a dozen indicators. As we want to restrict our indicator set to around ten, we choose to select endpoint indicators, which allow covering the total environmental damage concisely. Selecting LCA endpoint indicators rather than midpoint indicators is doubly beneficial: focusing on meaningful environmental indicators for the preservation of our planet and restricting the number of performance indicators to help decision makers while encompassing all the midpoint impact categories, including the most popular one: climate changecontribution. Further adaptations of this method do not exclude calculating a complete midpoint set to assess the environmental impacts of resurfacing policies and, for instance, a climate change contribution indicator. 


\subsubsection{Selection of Endpoint Indicators}

We select the two operational environmental endpoint indicators from the method IMPACT World+ [66]: damage to ecosystems (renamed "biodiversity") and to human health. IMPACT World+ is the update of IMPACT 2002+, LUCAS and EDIP, and currently the most scientifically advanced characterization method in LCA [67]. The IMPACT World+ biodiversity damage indicator covers the effects on biodiversity of (short- and long-term) marine, freshwater and soil acidification; freshwater and marine eutrophication; land use; ecotoxicity (short- and long-term); climate change (short- and long-term); ionizing radiation and heat pollution affecting water quality and water availability (for terrestrial and aquatic freshwater ecosystems). The biodiversity loss calculated is expressed in PDF.m².yr: it corresponds to the potentially disappeared fraction of species over a surface area of one squared meter over one year. The IMPACT World+ indicator for damage to human health includes the following effects: climate change (short- and long-term), carcinogenic and non-carcinogenic toxicities (short- and long-term), ionizing radiation, ozone layer depletion, formation of fine particulates and photochemical oxidants and availability of water. This indicator is expressed in $D A L Y$, meaning disability-adjusted life years. One DALY is equivalent either to one year of potential life lost through premature death or one year of productivity lost as a result of incapacity. Note that the human health damage indicator includes the impact of air pollution over the entire supply chain of road maintenance consumption and road usage. Air pollution due to roads is a major public health issue, even more when highly trafficked and localized in densely populated areas. However, manufacturing is also a major source of air pollution: we chose an indicator that does not discriminate the damage to human health due to air pollution around roads and around facilities worldwide (where, for instance, spare parts or fuel are produced), whereas socioeconomic appraisals only consider local pollutions.

A third endpoint indicator focusing on damage to non-renewable resources and calculated with the ReCiPe method [68] comes to complete this environmental set of indicators. The latter, expressed in dollars, counts the economic impacts relating to the consumption of fossil and mineral resources, using a marginal cost approach. This approach is underpinned by the notion of resource scarcity: the scarcer a resource, the more its consumption will generate additional future extraction costs. ReCiPe offers the most advanced resource damage indicator, as it is an update of the Eco-Indicator and CML methods [67].

\subsubsection{Calculation of the Metrics}

Equation (13) is the formula to calculate the impact of a unitary consumption $I_{j, k, o}$ for each type of consumption $k$-a type of tire, suspension system or fuel needed to travel one kilometer-per type of vehicle $j$, for each type $o$ of the three damage indicators. It sums the products of each flow of consumption or emissions flow $_{\mathcal{c}}$ listed in the corresponding consumption life cycle inventories by characterization factor $C F_{c, o}$ obtained from the methods IMPACT World+ or ReCiPe, we.

$$
I_{j, k, o}=\sum \text { flow }_{c} \times C F_{c, o}
$$

The environmental impact of type $o$ related to switching from a BAU resurfacing scenario to an alternative scenario is then calculated by multiplying the unitary impact of each type of consumption $k$ by the number of units consumed over the assessment period for the total traffic. Consumption in one resurfacing scenario can be calculated with Equations (3)-(6).

\subsection{Social Metrics}

Two social indicators are considered in the method: users' time savings and the impact of road noise on residents' health. The latter could be considered an environmental 
indicator. However, as it involves the local population exposed to the road's traffic, it is considered a social indicator.

\subsubsection{Road Noise Health Impact Indicator}

The method includes an indicator of the impact of road noise on local residents' health $D A L Y_{\Delta t}$. It combines the road noise model developed in the noise inventory section of the article with a road noise LCA model developed by Meyer (2017). More specifically, we will use Meyer's characterization factors $C F_{\Delta t}$ that relate the noise energy $E_{\Delta t}$ emitted by the road to human health damage according to Equation (14), with $C F_{\text {day }}=6.61 \times 10^{-7} \mathrm{DALY} / J(A)$ and $C F_{\text {night }}=1.25 \times 10^{-5} \mathrm{DALY} / J(A)$.

$$
\begin{gathered}
D A L Y_{\Delta t}=E_{\Delta t} \times C F_{\Delta t}=W_{\Delta t} \times \Delta t \times C F_{\Delta t}=W_{\text {day }} \times \\
\Delta t(\text { day }) \times C F_{\text {day }}+W_{\text {night }} \times \Delta t(\text { night }) \times C F_{\text {night }}
\end{gathered}
$$

The residents' health damage due to traffic noise will be calculated over the assessment period according to Equation (15).

$$
\text { HealthDamage } \text { residents }=\int_{t_{0}}^{t_{f}} D A L Y_{\Delta t} d t
$$

Contrary to air pollution impacts on human health that are considered over the entire supply chain, for this indicator, we calculate the impact of road noise on human health of people living around the road, due to a lack of database on noise emissions of different activities.

\subsubsection{Users' Time Saving Indicator}

This indicator considers, based on the resurfacing program as well as fuel consumption, tire and suspension wear, the time spent by users in roadwork zones but also in journeys to gas stations or garages for vehicle maintenance and operation.

We use Equation (16) to calculate the time loss for a vehicle of type $j$ due to a work zone, with $\theta_{\text {alternative, } j}$ the time to cross the work zone during construction for the type of vehicle $j$ and $\theta_{\text {standard }, j}$ the standard time to cross the section. $\theta_{\text {alternative }, j}$ can relate to time lost due to congestion, construction traffic lights, reduced speed limitations or detours.

$$
\text { TimeLoss }_{\text {works }, j}=\theta_{\text {works }, j}-\theta_{\text {standard }, j}
$$

Then, the time lost on the road section over the assessment horizon is calculated by summing the time lost for the four types of vehicles $j$ and all the traffic during the $\mathrm{n}$ resurfacing operations, with $q_{j}(t)$ the hourly traffic of type $j$ vehicles, $\Delta t \_m$ the duration of the resurfacing operation $\mathrm{k}$ and $N_{k}$ the number of resurfacings of type k over the assessment period, as shown in Equation (17).

$$
\text { TimeLoss }_{\text {works }}=\sum_{k} \sum_{j} \text { Time }_{\text {loss }, j} \times q_{j}(t) \times N_{k} \Delta t \_m_{k}
$$

On the specific road network of type $i$, the total time lost due to vehicle consumption of type $c$ (tires, shock absorbers or fuel) is calculated with Equation (18) from $N_{c}$, the vehicle spare part consumption in number of total replacements of tires and shock absorbers or the volumes of $100 \mathrm{~L}$ of fuel for the vehicle of type $j$, and the estimated duration of the various operating and maintenance activities $O D_{c, j}$, with $c=1$ relating to tire consumption, $c=2$ to shock absorber consumption and $c=3$ to fuel consumption.

$$
\begin{gathered}
\text { TimeLoss }_{\text {vehicle consumptions }, i}=\sum_{j} \sum_{c} N_{c} \times O D_{c, j}=\sum_{j} T C_{i, j} \times O D_{1, j}+ \\
\sum_{j} S A C_{i, j} \times O D_{2, j}+\sum_{j} \frac{F C_{i, j}}{100} \times O D_{3, j}
\end{gathered}
$$


The users' time savings generated by an alternative resurfacing scheme compared to a reference are calculated using Equation (12) based on Equation (19):

$$
\text { TimeLoss }_{u s e r s}=\text { TimeLoss }_{\text {vehicle }} \text { consumptions }+ \text { TimeLoss }_{\text {works }}
$$

\subsection{Economic Metrics}

Based on resurfacing operations and vehicle consumption, we calculate the economic impacts of resurfacing programs, i.e., their macroeconomic effects and their financial consequences for the stakeholders concerned: the road operator, users and government. This requires cost models for vehicles and resurfacing consumption.

\subsubsection{Users' Costs}

The excess cost to use their vehicles for the road users Vehicle Expenses users $_{\text {, discounted }}$ over time at a rate $r$, can be calculated over the assessment period by multiplying each type $c$ of excess consumption $E E_{k}$-namely, $F C_{k}$ the excess fuel consumption of type $k, T C_{k}$ the number of tires of type $k$ overconsumed and $S A C_{k}$ the number of shock absorbers of type $k$ consumed-by their costs $C_{k}(t)$ in constant currency, following Equation (20).

$$
\text { VehicleExcessExpenses }_{\text {users }}=\int_{T=t_{0}}^{t_{f}} \sum_{k} \frac{1}{(1+r)^{T-t_{0}}} \times E E_{k}(t) \times C_{k}(t)
$$

By default, we propose to consider a discount rate $a$ equal to the government's 10-year borrowing rate, as it represents the household financial market reality.

\subsubsection{Road Operator's Costs}

The cost to maintain the road for the operator MaintenanceExpenses operator, $_{\text {, discounted }}$ over time at a rate $r$, can be calculated over the assessment period by multiplying the surfaces of the road maintained using the resurfacing technique $k, R W D_{k}(t)$, by $C_{k}(t)$, the cost of this technique per square meter over time in constant currency, following Equation (21).

$$
\text { Maintenance Expenses } \text { operator }=\int_{T=t_{0}}^{t_{f}} \sum_{k} \frac{1}{(1+r)^{T-t_{0}}} \times R W D_{k}(t) \times C_{k}(t)
$$

By default, we propose to consider a discount rate $r$ equal to the rate of return of the operator if it is a private company or to the government's 10-year borrowing rate if the road is publicly operated.

\subsubsection{Domestic Production and Employment}

To calculate domestic production and employment content indicators, we use Leontief's IOA method [26,69]. This method is used by governments to analyze the national accounts and produce their macroeconomic projections. It uses input-output (I/O) tables representing production by economic sectors and their mutual dependencies to calculate the macroeconomic impact of an economic shock, i.e., a change in demand on certain economic sectors.

First, we convert the previously calculated physical consumption items from Equations (3)-(6) into monetary flows employing cost models. These models are specific to a country and a period. The calculation can be conducted on an annual basis to potentially consider dynamic cost models. Then we apply the Leontief method using the I/O tables-generally supplied by the national ministries for the economy-to calculate an indicator of domestic production. It includes the annual sum of direct and indirect domestic production resulting from all demands for roadwork, fuel and service station changes to tires and suspension. Two formulas are central. First is that of the technical coefficients in Equation (22) to calculate the share of intermediate consumption of a sector per unit of production of this sector, with $\alpha_{i j}$ the coefficient corresponding to the share of expenditure on the product $i$ 
in production of branch $j, \operatorname{ter}_{i j}$ the matrix of intermediate consumption and $Y=\left[y_{j}\right]$ the matrix of production.

$$
\alpha_{i j}=\frac{\text { ter }_{i j}}{y_{j}}
$$

Then, the inverse Leontief relation, noted in Equation (23), makes it possible, from the matrix $A=\left[\alpha_{i j}\right]$ of technical coefficients and the vector $f$ of demand in a sector, to calculate the production sectorial effects $P$, with $I$ the identity matrix.

$$
P=(I-A)^{-1} \times f
$$

We can calculate an annual vector $f$ following Equation (24), where each element of the vector $f$ corresponds to the differential consumption (in currency) of a maintenance scenario compared to the reference. Hence, only the elements corresponding to pavement construction, vehicle maintenance, tires, shock absorbers and fuel consumption (or larger activities depending on the country economic nomenclature), will be nonempty.

$$
f_{i}=\int_{t_{0}}^{t_{f}} \Delta \text { consumption }_{i}(t) \times \text { UnitaryPrice }_{i}(t)
$$

The direct and indirect domestic production related to the maintenance scheme assessed can be calculated by summing the elements of vector $P$.

Then, based on the production vector, Equation (25) uses a national job content vector for the different economic sectors [JobContent], which is, most of the time, supplied by national ministries for one country economy to calculate domestic employment in Full-Time Equivalent (FTE) jobs, relating to these demands, on the supply chain within the country where road maintenance is performed.

$$
\text { FTE }=[\text { JobContent }] \times f
$$

\subsubsection{Tax Revenues}

The tax revenues collected on consumption for roadwork, fuel, tires and suspensions, discounted over time at a rate $r$, are calculated using Equation (26), with $f_{t}$ the demand vector for the year $T$ in constant currency and \%tax the tax rate vector (or a matrix in the case of tax rate variations over time), indicating the tax rate applicable for each type of consumption for the year $T$.

$$
\text { TaxRevenue }=\sum_{T=t_{0}}^{t_{f}} \frac{f_{T} \times \% \text { tax }_{T}}{(1+r)^{T-t_{0}}}
$$

By default, we propose to consider a discount rate $a$ relative to the government's 10 -year borrowing rate, as it represents the State financial market reality.

\subsubsection{Integrated National Economic Indicator}

A government is often interested in the total cost of a policy such as a road maintenance program, combining the financial flows for the different stakeholders. The NPV indicator can be used to estimate the financial interest for an actor or group of actors in an operation: the larger it is, the more financially interesting the operation. It is used in particular by decision makers and road managers to justify their decisions. We use this concept to calculate the multistakeholder financial impact of a maintenance scheme-for the operator, users and tax authority. We recall in Equation (27) the generic formula for calculating an NPV, i.e., the sum of the financial flows-incomes and expenses that we detailed earlier for all the stakeholders-in constant currency, which is actualized each year over the entire 
duration of the assessment period, with $E_{T}$ the expenses, $I_{T}$ the incomes planned for the year $t$, and $a$ the discount rate.

$$
\mathrm{NPV}=\sum_{T=t_{0}}^{t_{f}} \frac{I_{T}-E_{T}}{(1+r)^{T-t_{0}}}
$$

We suggest setting $r$ at $2.5 \%$, which is the risk-free discount rate recommended for the valuation of major investments in France. A risk-free rate choice allows us not to override the impact of future events [29] and, thus, to limit the burden of negative impacts for future generations.

\section{Discussion}

The geographical scope of the calculated impacts varies amongst the indicators: this scope goes from the close area around the road studied with the indicator of damage to human health due to road noise to a worldwide perimeter with the three LCA indicators, passing through a national scope with macroeconomic indicators. This heterogeneity of perimeters is partly justified by the scope of the impacts or the contribution of the various phenomena involved. For example, it is preferable to assess the environmental impacts at a global scale to limit the burden's geographic shifts. In addition, climate change, an important component of damage indicators, is based on global dynamics. On the contrary, it is likely that most of the noise changes linked to road maintenance policies are located around roads rather than around the manufacturing sites of road maintenance consumables because the impact of road maintenance policies on the production of these sites is marginal. Then, economic solidarity mostly occurs at a national level. However, the impacts of air pollution around roads and, more generally, in the country generate national socioeconomic impacts due to the cost of healthcare. Thus, comparing local or even national impacts to impacts in the rest of the world would advocate for or against further discretizing the two scales and potentially aggregate health damage due to noise and local air pollution into a resident human health damage indicator.

From a road management point of view, this method could benefit from future developments. It is for now restricted to the evaluation of resurfacing, but combined optimization of structural design and maintenance treatment scheduling over the lifespan of a road would allow for capturing the feedback effects between the mechanical behavior of the road structure and its surface layers. Such an approach will require advances in the field of road aging modeling. Next, the models linking road surface condition to vehicle fuel consumption and wear on tires and suspensions are central to the assessment mechanics in the method: these need to be developed and validated in regional conditions to enhance reliability of results. Uncertainty calculations could also be conducted to assess this reliability. Finally, a few indicators could be added. First is a user comfort indicator: riding comfort partly depends on the rolling course condition; nevertheless, we did not find any conclusive approach to propose an adequate quantitative indicator. Ideally, at the level of the road network, this user comfort indicator could be exploited in a more systemic way to calculate the impact of a resurfacing policy by considering the modification of the users' routes that may result from the evolution of the surface conditions. The selection of the route according to comfort can also imply differences in time, speed and consumption of travel, which are challenging to capture. Second is a pavement safety and reliability indicator quantifying the consequence of the road condition and, for example, cumulating the following costs: noninjury incidents, such as vehicle damage, goods breakage and damage for the freight, and monetized impact of injury accidents and fatalities. However, in practice, road safety depends on many factors, and, to our knowledge, the impact of the surface condition has not been decoupled from other factors [55]. Third is the tax revenue indicator, which could be refined to consider the financial impact of maintenance policies on social allowances from public authorities, e.g., on the unemployment allowances budget, depending on the employment performance of the policy. 


\section{Conclusions}

In this article, we present the first method of holistic sustainability assessment developed to our knowledge in the field of transportation. Notably, it integrates the three pillars of sustainability and considers important macroeconomic and other state-of-the-art indicators compared to existing sustainability rating systems of pavement and transportation projects [70]. It especially completes the existing approaches by adding the social, macroeconomic and financial aspects missing in the literature and by considering all the consequences of PVI - in particular the previously neglected environmental contributions of tire and suspension system wear. A novel method is also integrated to quantify the impact of road pavement resurfacing on traffic noise over time and, ultimately, damage to local residents' health. A set of indicators that is both comprehensive and concise is needed to support decision makers for whom triple bottom line performance remains a theoretical concept that they struggle to grasp in its entirety. Indeed, holistic sustainability can hardly be defined "above ground", i.e., in a generic way without looking at a specific system or object. Therefore, we have developed this method on the specific example of road maintenance policies, considering sustainability under the French social contract. While the calculation of the inventories (Section 4) is specific to road maintenance, and the PVI equations are calibrated in French conditions as an example, the performance calculation algorithm (Section 5) can be used to assess all kinds of transportation policies in any country. The selection of the relevant quantitative indicators is based on an integrated vision of sustainability by including all stakeholders highlighted by the literature review. The benefits of an alternative road maintenance policy compared to standard practices for these stakeholders are assessed on all three pillars of sustainable development. Thus, this report offers a positive or upbeat consequential approach to triple bottom line decision making, in the manner of the environmental handprint concept [71], that reverses the vision of the classic environmental footprint calculated in attributional LCA. Finally, this method can be used by any road manager or road owner willing to fully understand and tackle its sustainability responsibility.

Supplementary Materials: Detailed information referred to in the main text as accessible in the supplementary material can be found in the supplementary material document following this article. The following supporting information can be downloaded at: https:/ /www.mdpi.com/article/10.3 390/su14031513/s1. The code for the method is available on the GitHub repository accessible at the following link: https://github.com/Anne2B/PhD.git (accessed on 15 January 2022).

Author Contributions: Conceptualization: A.d.B., A.F. and F.L.; methodology: A.d.B., A.F. and F.L.; software: A.d.B.; validation: A.d.B.; formal analysis: A.d.B.; investigation: A.d.B.; resources: F.L.; data curation: A.d.B.; writing—original draft preparation: A.d.B.; writing—review and editing: A.d.B. and F.L.; visualization: A.d.B.; supervision: A.F. and F.L.; project administration: F.L.; funding acquisition: F.L. All authors have read and agreed to the published version of the manuscript.

Funding: This research was funded by the industrial chair ParisTech-VINCI in "eco-design of buildings and infrastructure".

Acknowledgments: The authors would like to thank the industrial chair ParisTech-VINCI in "eco-design of buildings and infrastructure", which funded the Ph.D. thesis from which this work was derived.

Conflicts of Interest: The authors declare no conflict of interest. 


\section{Abbreviations}

List of abbreviations. The abbreviations included in the text are reported alphabetically.

$\begin{array}{ll}\text { Abbreviation } & \text { Full Form } \\ \text { BAU } & \text { business-as-usual } \\ \text { DALY } & \text { disability-adjusted life years } \\ \text { DR } & \text { department road } \\ \text { EFC } & \text { excess fuel consumption } \\ \text { ER } & \text { express road } \\ \text { ETW } & \text { full-time equivalent } \\ \text { FTE } & \text { greenhouse gas } \\ \text { GHG } & \text { highway road } \\ \text { HR } & \text { heavy vehicle } \\ \text { HV } & \text { input-output } \\ \text { I/O } & \text { input-output analysis } \\ \text { IOA } & \text { international roughness index } \\ \text { IRI } & \text { life cycle assessment } \\ \text { LCA } & \text { life cycle cost analysis } \\ \text { LCCA } & \text { light commercial vehicle } \\ \text { LCV } & \text { large heavy vehicle } \\ \text { LHV } & \text { light vehicle } \\ \text { LV } & \text { Massachusetts Institute of Technology } \\ \text { MIT } & \text { net present value } \\ \text { NPV } & \text { national road } \\ \text { NR } & \text { passenger car } \\ \text { PC } & \text { potentially disappeared fraction } \\ \text { PDF } & \text { savement-vehicle interactions } \\ \text { PVI } & \text { small heavy vehicle } \\ \text { SAL } & \text { SHV }\end{array}$

\section{References}

1. Union Routière de France. Faits \& Chiffres 2018-Statistiques des Transports en France et en Europe. 2018. Available online: https:/ / fr.calameo.com/read/0039965789c6b488b8029 (accessed on 5 October 2021).

2. Visse, P.-E. Évolution du Budget Automobile des Ménages Français Depuis 1990. DGCCRF. 14 April 2013. Available online: http:/ / www.economie.gouv.fr / files / directions_services /dgccrf/documentation/dgccrf_eco/dgccrf_eco14.pdf (accessed on 8 December 2021).

3. Enquête Nationale Transport et Déplacements 2008. MEDDE. 2008. Available online: http://www.statistiques.developpementdurable.gouv.fr/transports/trv/deplacement-mobilite/mobilite-reguliere-locale.html (accessed on 28 October 2021).

4. CGDD. Chiffres Clés de L'énergie-Édition 2018. Commissariat Général au Développement Durable. 2018. Available online: https:/ / www.statistiques.developpement-durable.gouv.fr/sites/default/files/2018-10/datalab-43-chiffres-cles-de-l-energieedition-_2018-septembre2018.pdf (accessed on 7 November 2021).

5. CITEPA. Données D'émissions de Gaz à Effet de Serre Dans L'air en France Métropolitaine, Avril 2018, Format SECTEN. 2019. Available online: https://www.citepa.org/images/III-1_Rapports_Inventaires/SECTEN/CITEPA-chiffres-cles-2018-d.zip (accessed on 25 February 2019).

6. Bedeau, L.; Piquandet, J.; Duhautois, S.; Jonsson, E. Les Français et Les Nuisances Sonores. TNS Sofres-MEEDM. 2010. Available online: https:/ / www.tns-sofres.com/sites/default/files/2010.06.29-nuisances-sonores.pdf (accessed on 18 November 2021).

7. Chatti, K.; Zaabar, I. Estimating the Effects of Pavement Condition on Vehicle Operating Costs; Transportation Research Board: Washington, DC, USA, 2012. Available online: http:/ / onlinepubs.trb.org/onlinepubs/nchrp/nchrp_rpt_720.pdf (accessed on 7 November 2021).

8. Wang, T.; Lee, I.-S.; Kendall, A.; Harvey, J.; Lee, E.-B.; Kim, C. Life cycle energy consumption and GHG emission from pavement rehabilitation with different rolling resistance. J. Clean. Prod. 2012, 33, 86-96. [CrossRef]

9. Ulubeyli, S.; Kazanci, O. Holistic sustainability assessment of green building industry in Turkey. J. Clean. Prod. 2018, 202, 197-212. [CrossRef]

10. Chen, D.; Thiede, S.; Schudeleit, T.; Herrmann, C. A holistic and rapid sustainability assessment tool for manufacturing SMEs. CIRP Ann. 2014, 63, 437-440. [CrossRef] 
11. Landert, J.; Schader, C.; Moschitz, H.; Stolze, M. A Holistic Sustainability Assessment Method for Urban Food System Governance. Sustainability 2017, 9, 490. [CrossRef]

12. Hüging, H.; Glensor, K.; Lah, O. Need for a Holistic Assessment of Urban Mobility Measures-Review of Existing Methods and Design of a Simplified Approach. Transp. Res. Procedia 2014, 4, 3-13. [CrossRef]

13. Santero, N.J.; Masanet, E.; Horvath, A. Life-cycle assessment of pavements. Part I: Critical review. Resour. Conserv. Recycl. 2011, 55, 801-809. [CrossRef]

14. Mladenovič, A.; Turk, J.; Kovač, J.; Mauko, A.; Cotič, Z. Environmental evaluation of two scenarios for the selection of materials for asphalt wearing courses. J. Clean. Prod. 2015, 87, 683-691. [CrossRef]

15. Kucukvar, M.; Noori, M.; Egilmez, G.; Tatari, O. Stochastic decision modeling for sustainable pavement designs. Int. J. Life Cycle Assess. 2014, 19, 1185-1199. [CrossRef]

16. Vidal, R.; Moliner, E.; Martínez, G.; Rubio, M.C. Life cycle assessment of hot mix asphalt and zeolite-based warm mix asphalt with reclaimed asphalt pavement. Resour. Conserv. Recycl. 2013, 74, 101-114. [CrossRef]

17. Tatari, O.; Nazzal, M.; Kucukvar, M. Comparative sustainability assessment of warm-mix asphalts: A thermodynamic based hybrid life cycle analysis. Resour. Conserv. Recycl. 2012, 58, 18-24. [CrossRef]

18. Yu, B.; Lu, Q. Life cycle assessment of pavement: Methodology and case study. Transp. Res. Part D Transp. Environ. 2012, 17, 380-388. [CrossRef]

19. Cuenoud, J.L. Valorcol: Asphalt Mix Complying with Environment and Sustainable Development; RGRA: Paris, France, 2011.

20. Huang, Y.; Bird, R.; Heidrich, O. Development of a life cycle assessment tool for construction and maintenance of asphalt pavements. J. Clean. Prod. 2009, 17, 283-296. [CrossRef]

21. Chiu, C.-T.; Hsu, T.-H.; Yang, W.-F. Life cycle assessment on using recycled materials for rehabilitating asphalt pavements. Resour. Conserv. Recycl. 2008, 52, 545-556. [CrossRef]

22. Babashamsi, P.; Yusoff, N.I.M.; Ceylan, H.; Nor, N.G.M.; Jenatabadi, H.S. Evaluation of pavement life cycle cost analysis: Review and analysis. Int. J. Pavement Res. Technol. 2016, 9, 241-254. [CrossRef]

23. Santos, J. A Comprehensive Life Cycle Approach for Managing Pavement Systems. Ph.D. Thesis, Universidade de Coimbra, Coimbra, Portugal, 2015. Available online: https:/ / estudogeral.sib.uc.pt/bitstream/10316/30093/1/A\%20Comprehensive\%20 Life\%20Cycle\%20Approach\%20for\%20Managing\%20Pavement\%20Systems.pdf (accessed on 22 November 2021).

24. Ferreira, A.; Santos, J. LCCA System for Pavement Management: Sensitivity Analysis to the Discount Rate. Procedia-Soc. Behav. Sci. 2012, 53, 1172-1181. [CrossRef]

25. FHWA. Life-Cycle Cost Analysis in Pavement Design-In Search of Better Investment Decisions. US Department of Transportation-Federal Highway Administration, Pavement Division Interim Technical Bulletin Publication No. FHWA-SA-98079. 1998. Available online: https:/ / www.fhwa.dot.gov/infrastructure/asstmgmt/013017.pdf (accessed on 22 November 2021).

26. Leontief, W.W. Quantitative Input and Output Relations in the Economic Systems of the United States. Rev. Econ. Stat. 1936, 18, 105. [CrossRef]

27. Quirion, P. L'effet net sur L'emploi de la Transition Énergétique en France: Une Analyse Input-Output du Scénario Négawatt. CIRED, Document de Travail No 46-2013. 2013. Available online: http:/ /www2.centre-cired.fr/IMG/pdf/CIREDWP-201346.pdf (accessed on 2 October 2021).

28. Wubneh, M. US Highway 17 and Its Impact on the Economy of Eastern North Carolina; Urban \& Regional Planning Program Department of Geography East Carolina University: Greenville, NC, USA, 2008.

29. Quinet, E. L'Évaluation Socioéconomique des Investissements Publics. Rapport Final. Tome 1, 2013. Report. Commissariat général à la stratégie et à la Prospective. Available online: https:/ / www.strategie.gouv.fr/sites/strategie.gouv.fr/files / atoms / files/cgsp_evaluation_socioeconomique_29072014.pdf (accessed on 2 October 2021).

30. Leurent, F.; Windisch, E. Electric vs. Gasoline-Powered Vehicles: The Effects on a Nation's Economic Production and Public Finances. Routes/Roads, $N^{\circ}$ 357. 2013. Available online: https:/ / routesroadsmag.piarc.org/en/Routes-Roads-Magazine-Issue357-Climate-Change/1685, Routes-Roads-Magazine-Electric-Vs-Gasoline-Effects-Economy-Finances\#c3e63u7JL70 (accessed on 12 October 2021).

31. Fouqueray, E. Evaluation de L'impact Économique de Court Terme et de Moyen Terme des Chantiers de Grandes Infrastructures de Transport-Le cas de la LGV SEA Tours-Bordeaux. Ph.D. Thesis, Université de Poitiers-Faculté de Sciences Économiques, Poitiers, France, 2016.

32. de Bortoli, A. Consequential environmental Life Cycle Assessment and socio-economic analysis-hybridization test on a Parisian project of Bus Rapid Transit. In Proceedings of the AVNIR International Conference, Lille, France, 8-9 November 2016. [CrossRef]

33. Santos, J.; Flintsch, G.; Ferreira, A. Environmental and economic assessment of pavement construction and management practices for enhancing pavement sustainability. Resour. Conserv. Recycl. 2017, 116, 15-31. [CrossRef]

34. Moavenzadeh, F.; Berger, F.; Brademeyer, B.; Wyatt, R. The Highway Cost Model: General Framework; Massachusetts Institute of Technology Department of Civil Engineering Research Report No 75-4; Massachusetts Institute of Technology: Cambridge, MA, USA, 1975.

35. Abaynayaka, S.W.; Hide, H.; Robinson, R.; Rolt, J. Prediction of road construction and vehicle operating costs in developing countries. Proc. Inst. Civ. Eng. 1977, 62, 419-446. 
36. Kerali, R.; Parsley, L.; Robinson, R.; Snaith, M. Development of a Microcomputer based Model for Road Investment in Developing Countries. In Proceedings of the Second International Conference on Civil and Structural Engineering Computing, London, UK, 3-5 December 1985; pp. 83-86. [CrossRef]

37. Parsley, L.L.; Robinson, R. The TRRL, Road Investment Model for Developing Countries (RTIM2); TRLRL Laboratory Report 1057; Transport and Road Research Laboratory: Crowthorne, UK, 1982.

38. Bennett, C.R.; Greenwood, I.D. Volume 7: Modeling Road User and Environmental Effects in HDM-4, Version 3.0, International Study of Highway Development and Management Tools (ISOHDM), World Road Association (PIARC). 2003. Available online: http:/ / www.lpcb.org/index.php/documents/papers-and-reports/reports-and-books/194-2003-modelling-road-userand-environmental-effects-in-hdm-4/file (accessed on 17 October 2021).

39. Chong, D.; Wang, Y. Impacts of flexible pavement design and management decisions on life cycle energy consumption and carbon footprint. Int. J. Life Cycle Assess. 2016, 22, 952-971. [CrossRef]

40. Wang, T.; Harvey, J.T.; Kendall, A. Reducing greenhouse gas emissions through strategic management of highway pavement roughness. Environ. Res. Lett. 2014, 9, 034007. [CrossRef]

41. Bryce, J.; Katicha, S.; Flintsch, G.; Sivaneswaran, N.; Santos, J. Probabilistic Life-Cycle Assessment as Network-Level Evaluation Tool for Use and Maintenance Phases of Pavements. Transp. Res. Rec. J. Transp. Res. Board 2014, 2455, 44-53. [CrossRef]

42. Yu, B.; Gu, X.; Ni, F.; Guo, R. Multi-objective optimization for asphalt pavement maintenance plans at project level: Integrating performance, cost and environment. Transp. Res. Part D Transp. Environ. 2015, 41, 64-74. [CrossRef]

43. Yang, R.; Kang, S.; Ozer, H.; Al-Qadi, I.L. Environmental and economic analyses of recycled asphalt concrete mixtures based on material production and potential performance. Resour. Conserv. Recycl. 2015, 104, 141-151. [CrossRef]

44. Santos, J.; Bryce, J.; Flintsch, G.; Ferreira, A.; Diefenderfer, B. A life cycle assessment of in-place recycling and conventional pavement construction and maintenance practices. Struct. Infrastruct. Eng. 2014, 11, 1199-1217. [CrossRef]

45. Pellecuer, L.; Assaf, G.J.; St-Jacques, M. Influence of Pavement Condition on Environmental Costs. J. Transp. Eng. 2014, 140, 04014050. [CrossRef]

46. Guevara, C.A. Mode-valued differences of in-vehicle travel time Savings. Transportation 2016, 44, 977-997. [CrossRef]

47. Arnsperger, C.; van Parijs, P. Éthique Économique et Sociale; La Découverte: Paris, France, 2007.

48. Pigou, A. The Economics of Welfare, Macmillan and Co. London. 1932. Available online: http://www.econlib.org/library/ NPDBooks/Pigou/pgEW.html (accessed on 2 October 2021).

49. White, A. A Global Projection of Subjective Well-being: A Challenge to Positive Psychology? Psychtalk 2007, 56, 17-20.

50. Charte de L'environnement de 2004. 2005. Available online: https://www.legifrance.gouv.fr/Droit-francais/Constitution/ Charte-de-1-environnement-de-2004 (accessed on 17 October 2021).

51. Déclaration des Droits de l'Homme et du Citoyen de 1789. Available online: https:/ / www.legifrance.gouv.fr/Droit-francais / Constitution/Declaration-des-Droits-de-1-Homme-et-du-Citoyen-de-1789 (accessed on 2 December 2021).

52. Préambule de la Constitution du 27 Octobre 1946. Available online: https:/ / www.legifrance.gouv.fr/Droit-francais/Constitution/ Preambule-de-la-Constitution-du-27-octobre-1946 (accessed on 17 October 2021).

53. de Bortoli, A. Pour un Entretien Routier Durable: Prise en Compte des Conséquences de L'interaction ChausséeVéhicule Dans L'aide à la Décision des Politiques de Resurfaçage-Illustration par un cas Autoroutier Français [Toward Sustainable Road Maintenance: Taking into Account Vehicle-Pavement Interactions into the Decision-Making ProcessIllustration by a French Highway Case Study]. Université Paris Est-Ecole des Ponts ParisTech. 2018. Available online: https://www.researchgate.net/publication/333965224_Pour_un_entretien_routier_durable_prise_en_compte_des_ consequences_de_1 $\backslash \mathrm{T} 1 \backslash$ textquoterightinteraction_chaussee-vehicule_dans_ $1 \backslash \mathrm{T} 1 \backslash$ textquoterightaide_a_la_decision_des_ politiques_de_resurfacage_-_illustration_par_un_cas_autoroutier_fran (accessed on 28 November 2021).

54. Sapir, J. Théorie de la régulation, conventions, institutions et approches hétérodoxes de l'interdépendance des niveaux de decision. In Décisions Économiques; Economica: Paris, France, 1998; pp. 169-215.

55. Cerezo, V.; Gothié, M. Pavement Prediction Performance Models and Relation with Traffic Fatalities and Injuries. France. October 2008. Available online: https://www.researchgate.net/profile/Veronique_Cerezo/publication/281328 742_Pavement_prediction_performance_models_and_relation_with_traffic_fatalities_and_injuries/links /55faa08a08ae076 29e0427d3/Pavement-prediction-performance-models-and-relation-with-traffic-fatalities-and-injuries.pdf (accessed on 22 October 2021).

56. Bryce, J.; Santos, J.; Flintsch, G.; Katicha, S.; McGhee, K.; Ferreira, A. Analysis of rolling resistance models to analyse vehicle fuel consumption as a function of pavement properties. In Asphalt Pavements; CRC Press: Boca Raton, FL, USA, 2014; pp. 263-273. [CrossRef]

57. Yang, R. Development of a Pavement Life Cycle Assessment Tool Utilizing Regional Data and Introducing an Asphalt Binder Model; University of Illinois at Urbana-Champaign: Urbana, IL, USA, 2014. Available online: https://www.ideals.illinois.edu/bitstream/ handle/2142/50651/Rebekah_Yang.pdf?sequence=1 (accessed on 2 December 2021).

58. Wang, T.; Harvey, J.; Kendall, A. Network-Level Life-Cycle Energy Consumption and Greenhouse Gas from CAPM Treatments; University of California Pavement Research Center Research Report UCPRC-RR-2014-05; UC Davis: Davis, CA, USA, 2013. 
59. Tseng, E. Construction of Pavement Performance Models for Flexible Pavement Wheelpath Cracking and IRI for the California Department of Transportation New Pavement Management System. Master's Thesis, University of California Davis, Davis, CA, USA, 2012. Available online: https: / / search.proquest.com $/$ openview $/$ c0d1baa8afc851c4962b1399cc5d5b3b $/ 1$ ? pq-origsite= gscholar\&cbl=18750\&diss $=y$ (accessed on 24 November 2021).

60. McGhee, K.; Gillespie, J. Impact of a Smoothness Incentive/Disincentive on Hot-Mix Asphalt Maintenance Resurfacing Costs. FHWA/VTRC 06-R28, VTRC 06-R28. 2006. Available online: https://ntl.bts.gov/lib/37000/37300/37317/06-r28.pdf (accessed on 2 September 2021).

61. Zaabar, I.; Chatti, K. Calibration of HDM-4 Models for Estimating the Effect of Pavement Roughness on Fuel Consumption for U.S. Conditions. Transp. Res. Rec. J. Transp. Res. Board 2010, 2155, 105-116. [CrossRef]

62. Sétra. Road noise prediction-1-Calculating sound emissions from road traffic. Report Q-SETRA-11-ED13-FR+ENG, 120p, Reference SKU1916164304, Paris, France. 2009. Available online: https:/ /www.cerema.fr/fr/centre-ressources/boutique/roadnoise-prediction (accessed on 2 September 2021).

63. Sétra. Prévision du Bruit Routier 1-Calcul des Émissions Sonores Dues au Trafic Routier. Sétra. 2009. Available online: https:/ / www.cerema.fr/fr/centre-ressources/boutique/prevision-du-bruit-routier-calcul-emissions-sonores-dues-au (accessed on 2 October 2021).

64. International Organization for Standardization. ISO 14040:2006-Environmental Management_Life Cycle Assessment-Principles and Framework; ISO: Geneva, Switzerland, 2006.

65. International Organization for Standardization. ISO 14044:2006-Environmental Management_Life Cycle Assessment-Requirements and Guidelines; ISO: Geneva, Switzerland, 2006.

66. Bulle, C.; Margni, M.; Patouillard, L.; Boulay, A.-M.; Bourgault, G.; De Bruille, V.; Cao, V.; Hauschild, M.; Henderson, A.; Humbert, S.; et al. IMPACT World+: A globally regionalized life cycle impact assessment method. Int. J. Life Cycle Assess. 2019, 24, 1653-1674. [CrossRef]

67. Curran, M.A. Life Cycle Assessment Student Handbook; Wiley: Hoboken, NJ, USA, 2015.

68. Huijbregts, M.A.J.; Steinmann, Z.J.N.; Elshout, P.M.F.; Stam, G.; Verones, F.; Vieira, M.; Zijp, M.; Hollander, A.; van Zelm, R. ReCiPe2016: A harmonised life cycle impact assessment method at midpoint and endpoint level. Int. J. Life Cycle Assess. 2017, 22, 138-147. [CrossRef]

69. Leontief, W. Environmental Repercussions and the Economic Structure: An Input-Output Approach. Rev. Econ. Stat. 1970, 52, 262-271. [CrossRef]

70. FHWA. State of the Practice on Sustainability Rating Systems; Federal Highway Administration, Federal Highway Administration: Washington, DC, USA, 2019.

71. Norris, G. Handprint-Based NetPositive Assessment; Center for Health and the Global Environment, Harvard T.H. Chan School of Public Health: Cambridge, MA, USA, 2015. Available online: https://hwpi.harvard.edu/files/chge/files/handprint-based_ netpositive_assessment.pdf (accessed on 10 October 2021). 